\title{
Angiographic findings and surgical treatments of coronary artery involvement in Takayasu arteritis
}

\author{
Masahiro Endo, $\mathrm{MD}^{\mathrm{a}}$ \\ Yasuko Tomizawa, MD \\ Hiroshi Nishida, $\mathrm{MD}^{\mathrm{a}}$ \\ Shigeyuki Aomi, MDa \\ Makoto Nakazawa, MD ${ }^{\text {b }}$ \\ Yukio Tsurumi, MD ${ }^{\mathrm{c}}$ \\ Masatoshi Kawana, MDc \\ Hiroshi Kasanuki, $\mathrm{MD}^{\mathrm{c}}$
}

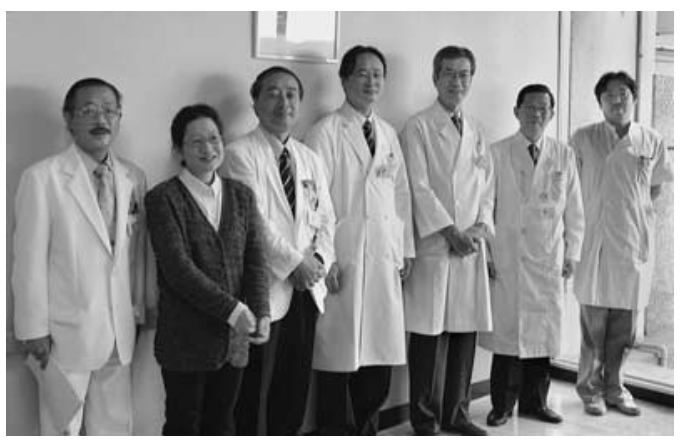

Endo, Tomizawa, Nishida, Aomi, Nakazawa, Kasanuki, Tsurumi (left to right)
Background: Takayasu arteritis is associated with a low incidence of coronary artery involvement, such as stenosis, obstruction, aneurysm, and coronary steal syndrome, but coronary ischemia can be fatal.

Methods: Between 1972 and April 2001, 81 of 130 patients given a diagnosis of Takayasu arteritis underwent selective coronary angiography, and among them, 31 patients ( 4 male and 27 female patients; mean age, $41.1 \pm 13.2$ years) had abnormal coronary angiographic findings and were recruited for this study.

Results: Abnormal coronary findings consisted of 24 coronary artery stenoses of greater than 75\%, 3 coronary artery-bronchial artery anastomoses, 3 aneurysmal coronary ectasias, and 1 combined coronary ectasia and anastomosis. Among 24 patients with coronary stenosis, the ostium was most frequently involved (87.5\%). Twenty-three of 24 patients with coronary artery stenoses were treated surgically. The mean follow-up duration was $9.65 \pm 6.9$ years, with a $100 \%$ follow-up rate. Four fistulas and 4 aneurysms in 7 patients were not treated surgically. Coronary steal phenomenon was always associated with occluded pulmonary arteries and pulmonary hypertension. Aneurysmal coronary ectasia was related to severe aortic hypertension with or without aortic regurgitation and atypical coarctation. There were $2(8.7 \%)$ in-hospital deaths and 3 $(13 \%)$ late deaths. The actuarial survival rate, including in-hospital deaths, was $86.5 \% \pm 7.3 \%$ at 5 years and $81.4 \% \pm 8.4 \%$ at 10 years.

From the Departments of Cardiovascular Surgery, ${ }^{\mathrm{a}}$ Pediatric Cardiology, ${ }^{\mathrm{b}}$ and Cardiology, ${ }^{\mathrm{c}}$ Heart Institute of Japan, Tokyo Women's Medical University, Tokyo, Japan.

Received for publication April 16, 2002; revisions requested July 10,2002 ; revisions received Aug 4, 2002; accepted for publication Aug 28, 2002.

Address for reprints: Masahiro Endo, MD, Department of Cardiovascular Surgery, Heart Institute of Japan, Tokyo Women's Medical University, 8-1, Kawada, Shinjuku, Tokyo 162-8666, Japan (E-mail: ENDO@ hij.twmu.ac.jp).

J Thorac Cardiovasc Surg 2003;125:570-7

Copyright $(\odot 2003$ by The American Association for Thoracic Surgery

$0022-5223 / 2003 \$ 30.00+0$

doi:10.1067/mtc.2003.39
Conclusion: The incidence of coronary abnormalities is relatively low in patients with Takayasu arteritis; however, surgical treatment is recommended for patients with coronary ostial stenoses because coronary ischemia can be one of the major causes of death.

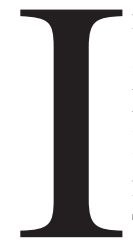

n 1908, Takayasu ${ }^{1}$ reported a case of a peculiar wreath-like arteriovenous anastomosis around the papillae of the ocular fundi in a young woman. During the discussion of Dr Takayasu's presentation, Drs Onishi and Kagoshima presented their experience of 2 patients with similar ocular fundus features, which showed the symptom of impalpable radial arteries. Takayasu arteritis has since been found in young women of Asian extraction and is still recognized as a disease with an unknown cause associated with arteritis predominantly at the aortic trunk, its major branches, and the pulmonary arteries. $^{2}$ 
Coronary artery involvement in Takayasu arteritis was first described by Frovig and Loken ${ }^{3}$ in 1951, and coronary artery bypass grafting (CABG) was first performed by Young and colleagues ${ }^{4}$ in 1973. The incidence of coronary lesions complicating Takayasu arteritis has been reported as $10.5 \%$ in autopsy cases ${ }^{2}$ and $9 \%$ in patients receiving a clinical diagnosis. ${ }^{5}$ Despite this incidence, coronary arterial stenosis is not included in Ishikawa's diagnostic criteria. ${ }^{6}$ The inflammatory process in the aorta has been implicated as the cause of stenosis in the coronary ostium, with manifestation of angina pectoris as the first symptom. ${ }^{7-10} \mathrm{We}$ report the abnormal coronary angiographic findings in patients with Takayasu arteritis and the coronary surgical treatments for these patients.

\section{Methods}

\section{Patients}

From 1972 to April 2001, approximately 240,300 patients attended the outpatient clinic at the Heart Institute of Japan, Tokyo Women's Medical University. Among them, approximately 130 $(0.05 \%)$ patients were given a diagnosis of Takayasu arteritis. Eighty-one patients with Takayasu arteritis had selective coronary angiography because of chest pain, ST-T-segment changes on electrocardiography, cardiomegaly caused by atypical coarctation, aortic regurgitation, severe stenosis of systemic arteritis, and renovascular hypertension. Thirty-one patients with abnormal coronary findings on selective angiograms were recruited in the present study, and the other 50 patients with angiographically normal coronary arteries were excluded.

The subjects were all Japanese and consisted of 4 male and 27 female patients aged 11 to 63 years (mean age, $41.1 \pm 13.2$ years). Twenty-nine (93.5\%) patients had onset of symptoms or clinical findings at 40 years of age or younger, and $2(6.5 \%)$ patients had unstable angina as the first symptom at 40 years of age or older. Twenty $(64.5 \%)$ patients were diagnosed by using Ishikawa's definitive criteria. The remaining $11(35.5 \%)$ patients showed no "weakness of radial pulse," but 9 met Ishikawa's minor criteria, and 2 did not meet either Ishikawa's major or minor criteria. In the last 2 patients, B52 or DQ-1 haplotypes were identified, and stenosis in the left main coronary artery (LMCA) ostium and abnormal wall thickening in the ascending aorta were observed at coronary revascularization. These 2 patients were given a diagnosis of Takayasu arteritis on the basis of histologic findings of surgical specimens and specific HLA haplotypes. One of these 2 patients (patient 10 in Table 1) showed "weakness of radial pulse" at 19 years postoperatively. Haplotypes of HLA were determined in 8 patients (Table 1).

Preoperative carotid evaluation in this study revealed stenosis in the common carotid artery in 2 patients and in the distal brachiocephalic artery in 2 patients.

Patients suspected of Bechet syndrome or Sjogren disease were excluded in this study. All patients had negative serologic test results for syphilis and rheumatoid factors. All had no history of Kawasaki disease or clinical findings of pseudoxanthoma elasticum.
TABLE 1. HLA haplotypes

\begin{tabular}{ll}
\hline Patient no. & \multicolumn{1}{c}{ HLA haplotypes } \\
\hline 10 & A31, B46, B52 CW1, DR8, DR15, D06 \\
11 & A2, A24, B52, B56, CW4, -D01 \\
19 & A24, A31, B35, B52, CW3, DR8, D01 \\
21 & A2, A24, B15, B52, CW3, DR2, DR14, D01 \\
22 & A21, A33, B44, B61, CW3, DR14, D01 \\
28 & A24, A33, B44, B52, DR13, DR15, D06 \\
29 & A31, B39, B62, CW1, DR8, D01 \\
30 & A24, B46, B52, DR2, DR9, D01 \\
\hline
\end{tabular}

\section{Diagnostic Angiography}

Abnormal coronary angiographic findings were defined as stenosis of greater than $75 \%$, coronary aneurysm, ectasia, and coronary steal phenomenon. Abnormal coronary findings in the 31 patients consisted of 24 stenoses of greater than $75 \%, 3$ coronary arterybronchial artery anastomoses, 3 aneurysmal coronary ectasia, and 1 combined anastomosis and ectasia. The relationships between the types of abnormal coronary angiographic findings and the clinical signs were analyzed.

\section{Preoperative and Postoperative Steroids}

Preoperative steroids $(30-40 \mathrm{mg} / \mathrm{d}$ prednisone) were used in 5 patients in the active stage of inflammation (defined as body temperature $>38^{\circ} \mathrm{C}$, C-reactive protein level $>5 \mathrm{mg} / \mathrm{dL}$, and erythrocyte sedimentation rate $>50 \mathrm{~mm} / \mathrm{h}$ ). In these patients prednisone was tapered to $10 \mathrm{mg} / \mathrm{d}$ until the chronic stage of inflammation in 3 patients, and urgent coronary surgery was performed in 2 patients because of unstable angina during the active stage. Postoperative steroids were used in these 5 patients $(5 \mathrm{mg} / \mathrm{d}$ prednisone) and in another 3 patients during recrudescence of inflammation.

\section{Surgical Treatment of Coronary Artery}

Twenty-three of 24 patients ( 5 male and 19 female patients, age range, 11-63 years; mean age, $41.0 \pm 15.1$ years) with coronary artery stenosis underwent coronary surgery. Nine had conventional CABG, 10 had CABG directly to the LMCA, 2 had transaortic endarterectomy, 1 had hybrid CABG (off-pump CABG with stent insertion), and 1 had ostial patch angioplasty. Four patients had conventional CABG and concomitant surgeries, including 1 Bentall operation, 1 aortic valve replacement, 1 extra-anatomic aortic bypass, and 1 bypass from the subclavian artery to the common carotid artery. The postoperative follow-up rate was $100 \%$, and the mean follow-up duration was $9.64 \pm 6.86$ years. The long-term actuarial survival rate was estimated by using the Kaplan-Meier method. Fistulas and aneurysms were not treated surgically because patients with fistulas had no angina, and aneurysms were diffuse.

During the operations, a piece of the ascending aortic wall near the LMCA in 1 patient and a piece of a hyperplastic intima and medium of coronary artery ostium in 2 patients were resected for histology. These specimens demonstrated granulomatous panarteritis with identifiable giant cells and lymphoplasmacytic infiltration. On the other hand, specimens from the best part of the 
TABLE 2. Sites of stenosis in the coronary arteries (24 patients)

\begin{tabular}{lrr}
\hline & & No. of patients \\
\cline { 2 - 3 } & All patients & Female patients \\
\hline Ostial stenosis & & 6 \\
Ostia of bilateral coronary arteries & 12 \\
Ostium of the left coronary artery & $3]$ & 6 \\
Ostium and proximal portion of coronary artery & 3 & 12 \\
Proximal portion of coronary artery & 24 & $1] 95 \%$ \\
Total & $24.5 \%$ & 1 \\
\hline
\end{tabular}

TABLE 3. Relationship between abnormal coronary angiographic findings and clinical observations in 31 patients with Takayasu arteritis

\begin{tabular}{|c|c|c|c|c|c|c|c|}
\hline \multirow[b]{2}{*}{ Abnormal coronary angiographic findings } & \multirow[b]{2}{*}{$\begin{array}{c}\text { Patient } \\
\text { no. }\end{array}$} & \multirow[b]{2}{*}{$\begin{array}{l}\text { Female* } \\
\text { patients }\end{array}$} & \multicolumn{5}{|c|}{ Abnormal clinical findings } \\
\hline & & & $\begin{array}{l}\text { Pulseless or } \\
\text { weak pulse }\end{array}$ & AR $>$ II & $\begin{array}{c}\text { Atypical } \\
\text { coarctation }\end{array}$ & $\begin{array}{c}\text { Occlusive } \\
\text { lesions of } \\
\text { pulmonary } \\
\text { artery with } \\
\text { PH }>60 \mathrm{~mm} \mathrm{Hg}\end{array}$ & $\begin{array}{l}\text { Severe aortic } \\
\text { hypertension } \\
>200 \mathrm{~mm} \mathrm{Hg}\end{array}$ \\
\hline Stenosis or occlusion & 24 & $20(83.3 \%)$ & $13(54.2 \%)$ & $3(12.5 \%)$ & $1(4.2 \%)$ & $1(4.2 \%)$ & 0 \\
\hline Aneurysmal coronary ectasia & 3 & $3(100 \%)$ & $3(100 \%)$ & $1(33.3 \%)$ & $1(33.3 \%)$ & 0 & $3(100 \%)$ \\
\hline Coronary steal phenomenon & 3 & $3(100 \%)$ & $3(100 \%)$ & $1(33.3 \%)$ & $2(66.7 \%)$ & $3(100 \%)$ & $1(33.3 \%)$ \\
\hline Combined coronary ectasia and steal phenomenon* & 1 & $1(100 \%)$ & $1(100 \%)$ & 0 & 0 & $1(100 \%)$ & $1(100 \%)$ \\
\hline Total & 31 & $27(87.1 \%)$ & 20 & 5 & 4 & 5 & 5 \\
\hline
\end{tabular}

$A R$, Aortic regurgitation; $P H$, pulmonary hypertension.

${ }^{*}$ Only one female patient had combined aneurysmal coronary ectasia and coronary steal phenomenon.

ascending aorta at the proximal anastomotic site for $\mathrm{CABG}$ in 5 patients were without specific changes.

\section{Special Surgical Techniques Used}

CABG directly to the LMCA was indicated in patients with left main ostial stenosis without calcification and patients in whom an internal thoracic artery (ITA) could not be used. A piece of saphenous vein (SV) was harvested from the thigh. The best part of the SV graft, that with large diameter and without a valve, was used. Bypass was performed from the posterior right side of the aorta to the LMCA through the transverse sinus.

Transaortic coronary ostial endarterectomy was indicated in patients with localized lesions at the coronary ostium and was performed according to our reported method. ${ }^{11}$ First, a percutaneous transluminal coronary angioplasty (PTCA) balloon catheter was inserted into a coronary artery with stenosis, and the stenotic portion was dilated and pulled out. Holding the stenotic portion with a piece of thread, the thick intima was resected piecemeal with a beaver knife. Finally, the remaining thick intima was punched out with a 4-mm Aorta-Punch (Scanlan International, St Paul, Minn).

Patch ostial angioplasty was indicated in patients without calcification at the LMCA and was performed by using the proximal portion of a free right ITA.

Hybrid CABG was indicated in patients in whom CABG with an SV graft was difficult because of a calcified porcelain aorta. Hybrid CABG consisted of preoperative stent insertion to the right coronary artery, off-pump CABG to the left anterior descending artery with an ITA, and bypass from the left subclavian artery to the left common carotid artery. Postoperative stenting was performed in the left circumflex artery.

\section{Postoperative Catheterization}

All patients were routinely scheduled for postoperative catheterization, and 22 patients underwent examination.

\section{Results}

\section{Clinical Findings by Type of Abnormal Coronary} Angiographic Finding

Coronary arterial stenosis of greater than $75 \%$. Twenty-four patients (4 male and 20 female patients) had coronary arterial stenoses. Twenty-one of 24 patients had ostial stenosis at the left main artery in 12 , at the ostia in the bilateral coronary arteries in 6 , and at the left main ostium and proximal portion of the coronary artery in 3 . In the remaining 3 patients stenosis was limited to the proximal portion of the coronary artery without ostial involvement (Table 2). Nineteen of 20 female patients had left main ostial stenoses.

Three of 4 male patients had a history of stroke, 2 had aortic regurgitation or annuloaortic ectasia plus aortic regurgitation, and 1 had an atypical coarctation.

Coronary steal phenomenon. Four female patients with a diagnosis of typical Takayasu arteritis had coronary steal 
syndrome (Table 3). When contrast medium was injected into the coronary artery, the flow was in the direction of the pulmonary bed area. All patients had multiple occlusive pulmonary arteries associated with pulmonary hypertension and a systolic blood pressure of greater than $60 \mathrm{~mm} \mathrm{Hg}$.

Patient 1 (Figure 1) was a 41-year-old woman with bilateral coronary steal phenomenon. Multiple occlusive lesions in the pulmonary arteries were associated with pulmonary hypertension of $70 \mathrm{~mm} \mathrm{Hg}$ and an occlusive lesion in the renal artery. She died of right heart failure at the age of 63 years.

Coronary aneurysm and ectasia. Four female patients with a diagnosis of typical Takayasu arteritis according to Ishikawa's criteria had diffuse aneurysmal coronary ectasia. All had severe aortic hypertension with a systolic blood pressure of greater than $200 \mathrm{~mm} \mathrm{Hg}$. One had atypical coarctation. One patient had aortic regurgitation (III).

Patient 2 (Figure 2) was a 46-year-old woman with fusiform-shaped dilatation of both coronary arteries, with the largest internal diameter being $25 \mathrm{~mm}$. She had mild atypical coarctation but no chest pain. She died of pneumonia at 66 years of age.

\section{Early Results of Coronary Surgical Treatments}

Surgical treatments in patients with stenoses consisted of isolated coronary revascularization in 19 patients and coronary revascularization with concomitant surgical intervention in 4 patients.

Isolated coronary surgery. Nineteen patients had isolated coronary revascularization, including 6 cases of conventional CABG with 14 distal anastomoses, 10 cases of CABG directly to the LMCA with 3 supplemental conventional distal anastomoses, 2 cases of transaortic endarterectomy, and case of 1 patch ostioplasty. For conventional CABG with SV or ITA grafts, 17 distal anastomoses had graft flows ranging from 20 to $110 \mathrm{~mL} / \mathrm{min}$ (mean, $80.2 \pm$ $23.4 \mathrm{~mL} / \mathrm{min}$ ). The graft flow of 10 patients receiving CABG directly to the LMCA ranged from 80 to $340 \mathrm{~mL} /$ min (mean, $189.7 \pm 83.3 \mathrm{~mL} / \mathrm{min}$ ). The graft flow of conventional $\mathrm{CABG}$ was significantly lower than that of CABG directly to the LMCA $(P=.0014)$.

The early patency rate was $100 \%$ (29/29), including transaortic endarterectomy and patch ostioplasty. One case of anastomotic stenosis required PTCA and was dilated successfully. One patient who had an uneventful perioperative course died of ventricular fibrillation during intensive care unit stay, and the other 18 were uneventful.

Patient 3 (19-year-old woman in 1981) was in Canadian Cardiovascular Society class 4 and had a 99\% stenosis at the left main ostium with good collaterals from the right coronary artery (Figure 3, $A$ and $B$ ). Transaortic endarterectomy was performed. Postoperative angiography showed a widely patent left main ostium (Figure 3, $C$ and $D$ ). She has had no chest pain since the operation.
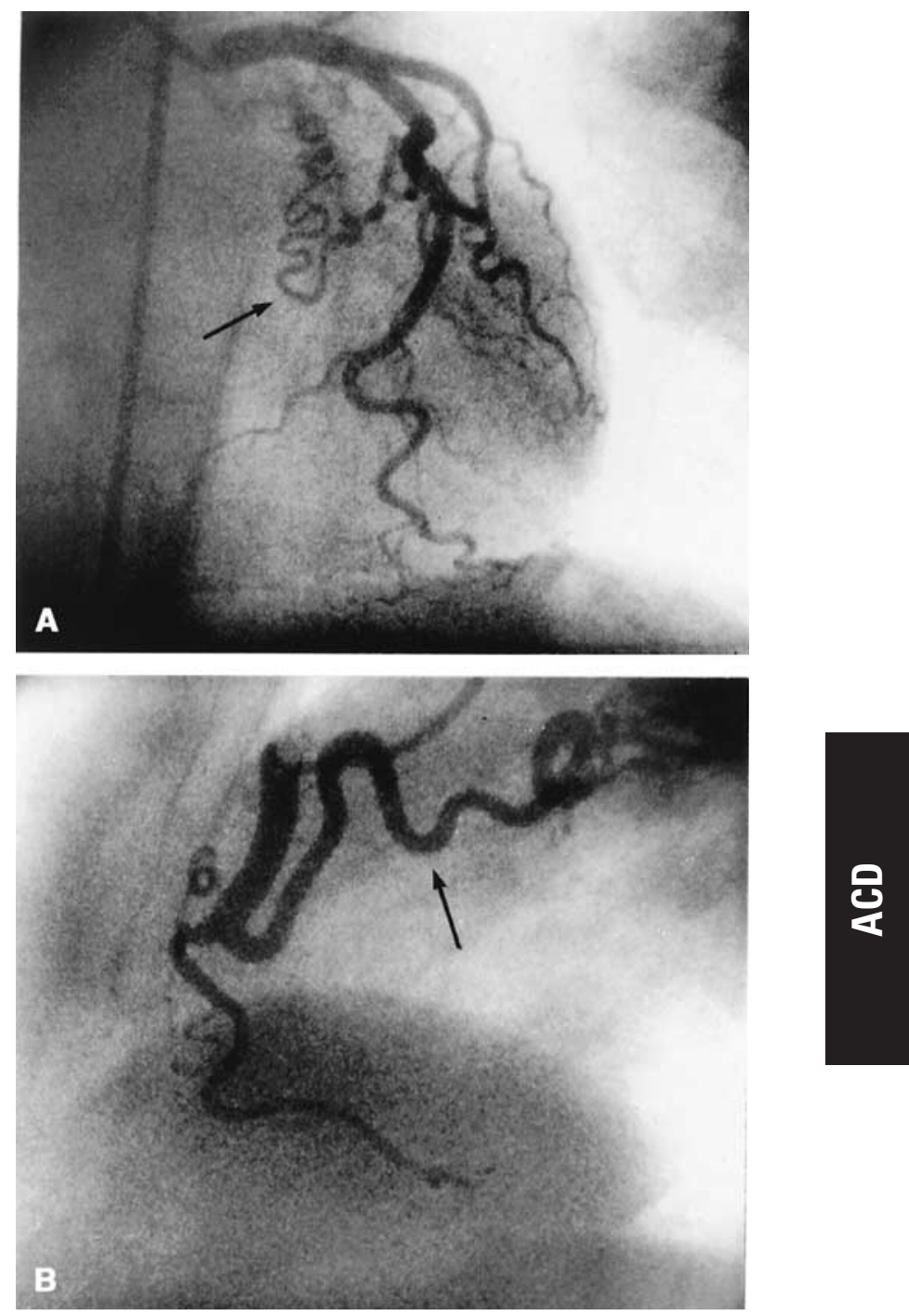

Figure 1. Angiograms showing coronary artery-bronchial artery anastomoses (arrows) in patient 1: A, right coronary artery; B, left coronary artery.

Conventional CABG associated with concomitant surgery. Four patients had conventional CABG (7 distal anastomoses with $5 \mathrm{SV}$ grafts and 2 ITA grafts) and concomitant surgery. There was one hospital death caused by cerebral infarction because of relatively low-pressure extracorporeal circulatory perfusion. This patient had a past history of old cerebral infarction caused by stenoses at the brachiocephalic artery and the left mid common carotid artery.

The overall early graft patency in the coronary artery position was $85.7 \%$ (6/7), with one SV graft occlusion.

\section{Late Results}

Late results are shown in Figure 4. There were 3 late deaths: 1 sudden death (3.1 years after the operation), 1 cardiac 

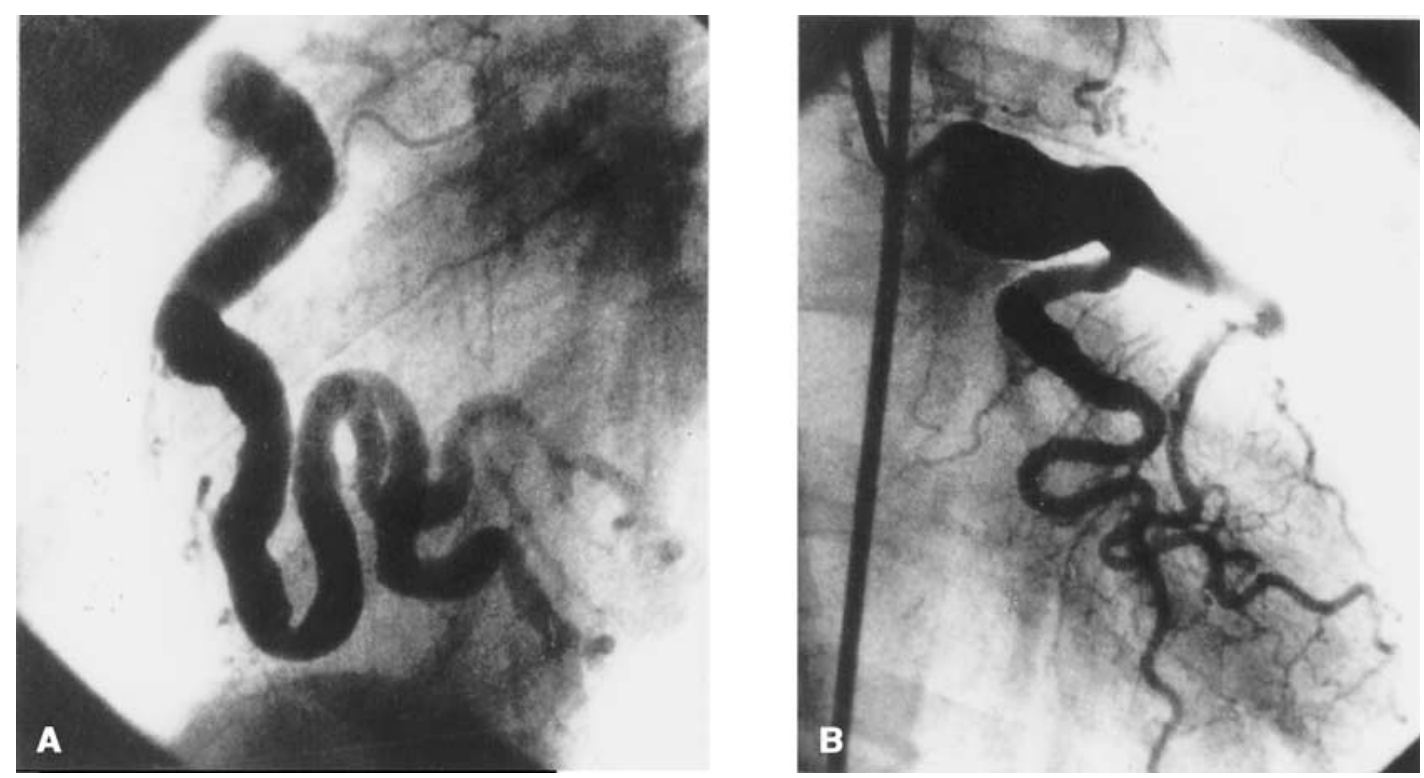

Figure 2. Angiograms showing dilatation of the right and left coronary arteries in a fusiform shape in patient 2: $A$, right coronary artery; $B$, left coronary artery. The largest internal diameter is $\mathbf{2 5} \mathbf{~ m m}$ in the left coronary artery.

death caused by congestive heart failure (5.5 years after the operation), and 1 noncardiac death caused by ileus (11.4 years after the operation). Re-CABG was performed in 2 patients: 1 patient with conventional CABG after 4 months and 1 with CABG directly to the LMCA after 13.5 years. The actuarial survival rate, including in-hospital deaths, was $86.5 \% \pm 7.3 \%$ at 5 years and $81.4 \% \pm 8.4 \%$ at 10 years. The cardiac event-free rate (free from cardiac death, reCABG, PTCA, and new myocardial infarction) was $77.8 \%$ $\pm 8.8 \%$ at 5 years and $72.6 \% \pm 9.6 \%$ at 10 years. Two patients with transaortic coronary ostial endarterectomy at 20 and 13 years and 1 patient with patch ostial angioplasty at 7 years had uneventful postoperative courses without symptoms.

\section{Discussion}

The incidence of coronary lesions complicating Takayasu arteritis is relatively low; however, ischemia caused by coronary lesions is one of the major causes of death. ${ }^{12} \mathrm{Nasu}^{2}$ reported the incidence of coronary lesions complicating Takayasu arteritis to be $10.5 \%$ ( $8 / 76$ autopsy cases). On the other hand, Nagata ${ }^{12}$ observed cardiac lesions in $91.5 \%$ : cardiomegaly in $81.7 \%$, aortic regurgitation in $14.6 \%$, and myocardial infarction in $12.2 \%$ of 82 autopsy cases. Ishikawa $^{6}$ has established certain criteria for the diagnosis of Takayasu arteritis, but coronary-related lesions are not included. Before 1977, occlusive coronary artery lesions were found occasionally in autopsy cases. ${ }^{2,5}$ More recently, complicating coronary lesions were increasingly observed and reported in $45 \%$ of 82 autopsy cases of Takayasu arteritis, ${ }^{12}$ and $73 \%$ of occlusive coronary lesions were localized around the coronary ostium according to the review by Amano and Suzuki. ${ }^{13}$ Coronary ostial stenosis occurs as a result of the extension of inflammation-induced intimal proliferation and fibrous contraction from the ascending aorta and the coronary ostia. ${ }^{12}$

Patients with left main ostial stenosis complicating Takayasu arteritis require surgical treatment. The 3 surgical options are CABG, surgical angioplasty of the LMCA, and transaortic coronary ostial endarterectomy. The timing of the operation is important, and surgical treatment should be avoided during the active stage of inflammation in Takayasu arteritis. However, when patients have unstable angina, surgical treatment must be performed without delay because one of the major causes of death among patients with Takayasu arteritis is myocardial infarction. ${ }^{12}$

Takayasu arteritis is a disease of unknown cause affecting the aorta and its main branches segmentally. ${ }^{5}$ The in situ ITA should not be used as a graft for coronary revascularization because Takayasu arteritis is often accompanied by occlusion of subclavian arteries, even though it is well known that the long-term patency of the ITA graft is significantly higher than that of the SV graft in atherosclerotic patients. ${ }^{14}$ In patients with Takayasu arteritis, whose occlusive lesion of the subclavian artery is located more distal than the derivation of the ITA, the use of ITA grafts for coronary revascularization might be possible.

In a safety-first policy, conventional CABG is recommended. Sixty-one patients in the review by Amano and Suzuki ${ }^{13}$ and 19 patients in the report by Ando and coworkers $^{15}$ were treated with myocardial revascularization, and SV grafts were used in $80 \%$ of patients in the review by 

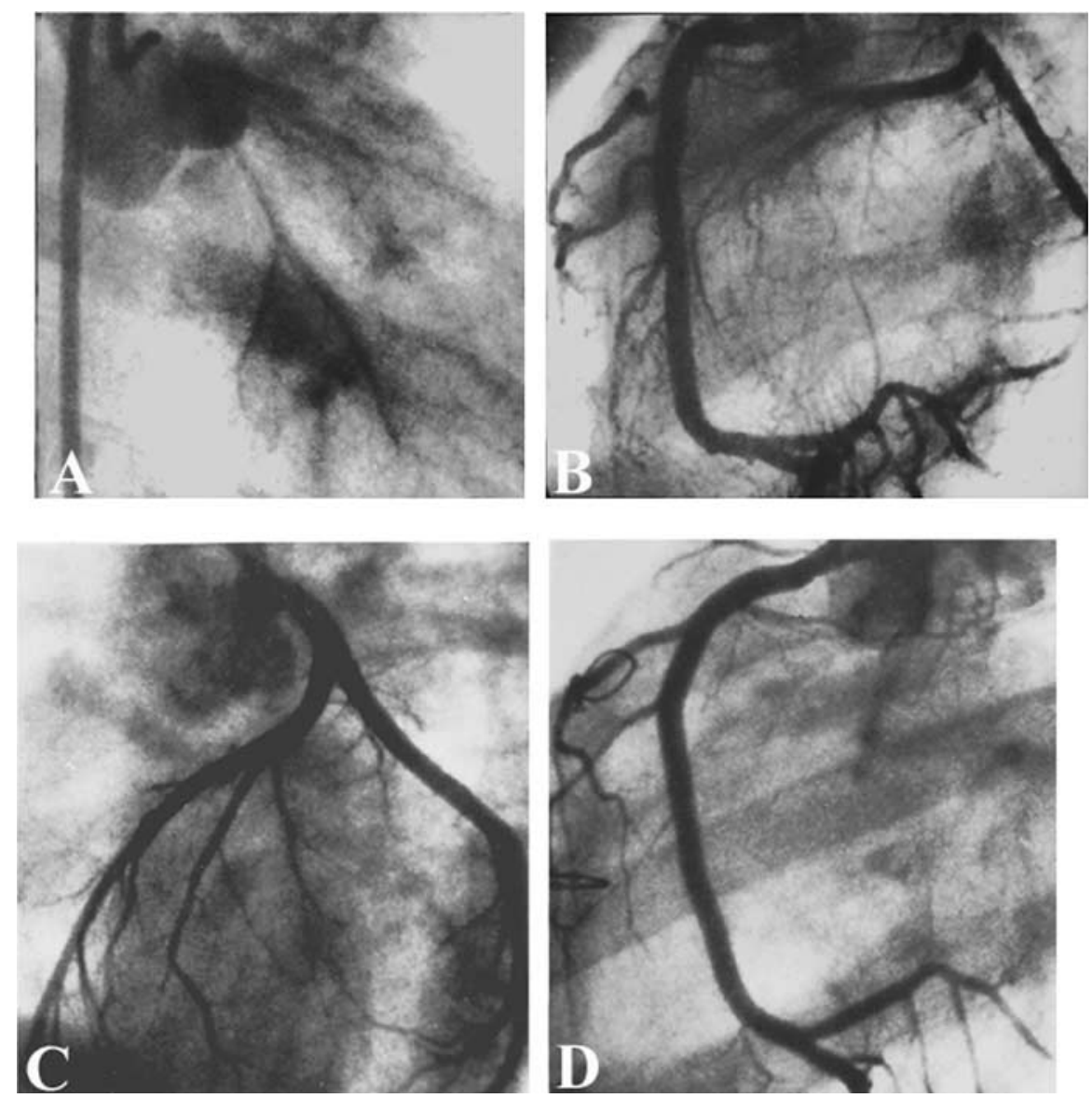

Figure 3. Preoperative angiograms showing a $99 \%$ stenosis at the left ostium (A) with good collaterals from the right coronary artery (B) in patient 3. Posttransaortic endarterectomy angiogram showing wide patency in the left coronary ostium: $C$, left coronary artery; $D$, right coronary artery. The collaterals from the right coronary artery to the left coronary artery disappeared after the operation.

Amano and Suzuki. ${ }^{13}$ However, the long-term graft patency with an SV vein graft was limited to $60 \%$ at 4 years in the report by Ando and coworkers. ${ }^{15}$ In one case we used adjunctive angioplasty rather than complete surgical revascularization, with the aim to improve patency because the diameter of the ITA graft was small and an SV graft is unsatisfactory in long-term patency. Conventional CABG is not the best choice when there is a macroscopic calcification at the ascending aorta.

In conventional CABG for Takayasu arteritis, graft occlusion occurs mainly at the proximal anastomotic site because of intimal thickening of the aorta. ${ }^{8,15,16}$ The use of a large-diameter SV graft anastomosed to the LMCA is recommended to obtain a big anastomosis with high flow and to avoid graft occlusion at the proximal anastomosis. However, because of technical difficulties, a few cases of CABG directly to the LMCA have been reported. ${ }^{13,17}$

Calcification of the proximal portion of the aorta and involvement of the LMCA might be contraindications for coronary ostioplasty. ${ }^{18}$ A piece of autologous pericardium, ${ }^{19}$ glutaraldehyde-treated pericardium, ${ }^{20}$ and an SV graft $^{10}$ have been used as a patch for coronary ostioplasty. We used a piece of the free proximal portion of the ITA as a patch, and there was no intimal hyperplasia. However, the choice of patch material remains unclear because of limited cases.

Transaortic coronary ostial endarterectomy in Takayasu arteritis was first reported by Endo and colleagues ${ }^{11}$ in 1982. According to these cases and a review, ${ }^{21}$ patients remain free of angina and cardiac events over the long term, and this method can be recommended for young patients. In the report by Ando and coworkers, ${ }^{15} 9$ patients who had transaortic endarterectomy were event free up to 4 years. However, perforation, bleeding, or hematoma at the junction of the aorta and the ostium of the coronary artery might occur during the surgical procedures as a result of excessive resection. Long-term follow-up is necessary because most surgical reports only include a few cases, and survival has been prolonged in patients with Takayasu arteritis. ${ }^{11,15,21}$ 


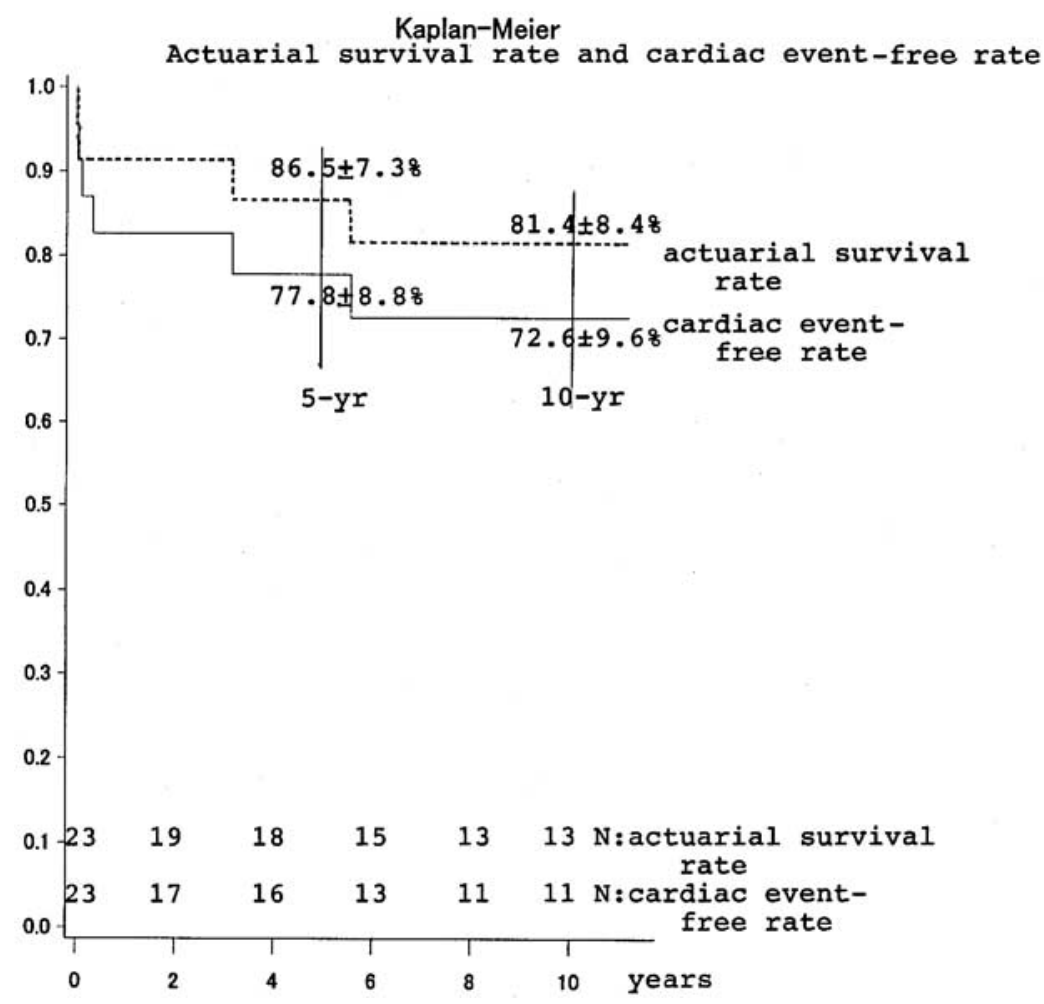

Figure 4. Actuarial survival rate and cardiac event-free rate of surgically treated patients with Takayasu arteritis with coronary artery stenosis (23 patients; Kaplan-Meier method).

Pulmonary hypertension could influence the morbidity and long-term mortality in Takayasu arteritis, and pulmonary artery involvement has been found in 56\% of patients with this disease. ${ }^{6}$ Coronary steal phenomenon in Takayasu arteritis is always associated with occlusive pulmonary arteries causing pulmonary hypertension. Surgical indication is suggested when patients have symptoms of angina pectoris caused by coronary steal syndrome. There were 2 surgical reports of patients having angina because of a large connection from the coronary artery to the bronchial artery ${ }^{22}$ or to the pulmonary artery. ${ }^{23}$ After the connections were ligated or divided surgically, symptoms were relieved, and the electrocardiography findings were normalized. However, the prognosis of patients with coronary steal phenomena is poor because of respiratory distress or right heart failure.

The present cases suggest a relationship between aneurysmal coronary ectasia and severe aortic hypertension of greater than $200 \mathrm{~mm} \mathrm{Hg}$, with or without aortic regurgitation, atypical coarctation, and calcified aorta. In a collective review by Matsubara and coworkers, ${ }^{24} 7$ autopsy cases of coronary aneurysm complicating Takayasu arteritis were found by 1992, and all were female patients. From our experience, however, ectasia itself is not an indication for surgical intervention.
Takayasu arteritis, with a strong predilection for women and specific geographic areas, has a significant association with HLA specificities. A population study on HLA typing revealed a high frequency of A24, B39, B52, and DQ-125,26 in Japanese patients with Takayasu arteritis. These haplotypes of HLA might be helpful in ruling out other types of aortitis.

Lesions associated with Takayasu arteritis are sometimes reversed with steroid therapy. Radial pulse became palpable, and the erythrocyte sedimentation rate and C-reactive protein levels tended to normalize in almost all patients in 2 reported series. ${ }^{27,28}$ Iga and associates ${ }^{29}$ reported a patient with Takayasu arteritis who had CABG as a result of unstable angina because of narrowing of the left main artery, and regression of ostial stenosis was observed after steroid therapy.

Patients with Takayasu arteritis show 3 types of abnormal coronary findings: coronary aneurysm, coronary steal phenomenon, and coronary ostial stenosis. Surgical treatment is recommended for patients with left coronary ostial stenosis because coronary ischemia can be a major cause of death. CABG directly to the LMCA, transaortic endarterectomy, and patch ostial angioplasty are treatments of choice for ischemia. 
We thank Dr Teresa Nakatani for assistance in preparing the manuscript and Mr Katsunori Shimada for assistance in data analysis.

\section{References}

1. Takayasu M. A case with unusual changes of the central vessels in the retina. Acta Soc Ophthalmol Jpn. 1908;12:554-5.

2. Nasu T. Takayasu's truncoarteritis in Japan. A statistical observation of 76 autopsy cases. Pathol Microbiol (Basel). 1975;43:140-6.

3. Frovig AG, Loken AC. Syndrome of obliteration of the arterial branches of the aortic arch due to arteritis. Acta Psychiatr Neurol Scand. 1951;26:313-37.

4. Young JA, Sengupta A, Khaja FU. Coronary arterial stenosis, angina pectoris and atypical coarctation of the aorta due to nonspecific arteritis. Treatment with aortocoronary bypass graft. Am J Cardiol. 1973;32:356-60.

5. Lupi HE, Sanchez TG, Marcushamer J, Mispireta J, Horwitz S, Vela JE. Takayasu's arteritis. Clinical study of 107 cases. Am Heart J. 1977;93:94-103.

6. Ishikawa K. Diagnostic approach and proposed criteria for the clinical diagnosis of Takayasu's arteriopathy. J Am Coll Cardiol. 1988;12: 964-72.

7. Hall S, Barr W, Lie JT, Stanson AW, Kazmier FJ, Hunder GG. Takayasu arteritis. A study of 32 North American patients. Medicine (Baltimore). 1985;64:89-99.

8. Cipriano PR, Silverman JF, Perlroth MG, Griepp RB, Wexler L. Coronary arterial narrowing in Takayasu's aortitis. Am J Cardiol. 1977;39:744-50.

9. Brantley B, Forman M, Virmani R. Diagnosis and treatment of Takayasu's arteritis. Prim Cardiol. 1990;16:47-50.

10. Swahn E, Karlsson JE, Fransson SG, Lindstrom F, Nylander E, Stahl E. Coronary ostial stenosis operated on by patch technique in a young woman with Takayasu arteritis and angina-pectoris. Eur Heart J. 1993; 14:1150-1.

11. Endo M, Ooteki H, Ishihara S, Koyanagi H, Takahashi K, Iseki K, et al. Transaortic intraoperative angioplasty (Gruntzig) and punch out endarterectomy. Cardioangiology. 1982;11:63-7.

12. Nagata S. Present state of autopsy cases of Takayasu's arteritis (aortitis syndrome) in Japan. J Jpn Coll Angiol. 1990;30:1303-8.

13. Amano J, Suzuki A. Coronary artery involvement in Takayasu's arteritis. Collective review and guideline for surgical treatment. J Thorac Cardiovasc Surg. 1991;102:554-60.

14. Endo M, Nishida H, Tomizawa Y, Kasanuki H. Benefit of bilateral over single internal mammary artery grafts for multiple coronary artery bypass grafting. Circulation. 2001;104:2164-70.
15. Ando M, Sasako Y, Okita Y, Tagusari O, Kitamura S, Matsuo H. Surgical considerations of occlusive lesions associated with Takayasu's arteritis. Jpn J Thorac Cardiovasc Surg. 2000;48:173-9.

16. Suzuki A, Amano J, Tanaka H, Sakamoto T, Sunamori M. Surgical consideration of aortitis involving the aortic root. Circulation. 1989; 80:I222-32.

17. Schurtz C, Lesbre JP. Takayashu's disease and double coronary artery involvement treated by bypass. Arch Mal Coeur Vaiss. 1982;75:793-9.

18. Dion R, Verhelst R, Matta A, Rousseau M, Goenen M, Chalant C. Surgical angioplasty of the left main coronary-artery. $J$ Thorac Cardiovasc Surg. 1990;99:241-50.

19. Morgan JM, Honey M, Gray HH, Belcher P, Paneth M. Angina pectoris in a case of Takayasu's disease: revascularization by coronary ostioplasty and bypass grafting. Eur Heart J. 1987;8:1354-8.

20. Nakano S, Shimazaki Y, Kaneko M, Taniguchi K, Miyamoto Y, Takami H, et al. Transaortic patch angioplasty for left coronary ostial stenosis in a patient with Takayasu's aortitis. Ann Thorac Surg. 1992;53:694-6.

21. Fujiwara T, Masaki H, Yamane H, Yoshida H, Katsumura T. Coronary ostial endarterectomy in Takayasu aortitis - confirmation of patency 9 years postsurgically. Jpn Circ J. 1992;56:556-9.

22. Kawasuji M, Murakami S, Watanabe Y, Iwa T. Coronary artery steal via a large anastomosis between the coronary and bronchial arteries successfully treated by surgical division. Thorac Cardiovasc Surg. 1984:32:119-21.

23. Kaneko Y, Goto T, Nishimura K, Goshi H, Udo J, Gojima Y, et al. Surgery of the coronary steal syndrome due to a fistula between the coronary artery and the pulmonary artery associated with the aortitis syndrome. Kyobu Geka. 1987;40:72-5.

24. Matsubara O, Kuwata T, Nemoto T, Kasuga T, Numano F. Coronary artery lesions in Takayasu arteritis: pathological considerations. Heart Vessels Suppl. 1992;7:26-31.

25. Numano F, Isohisa I, Kishi U, Arita M, Maezawa H. Takayasu's disease in twin sisters. Possible genetic factors. Circulation. 1978;58: 173-7.

26. Takeuchi Y, Matsuki K, Saito Y, Sugimoto T, Juji T. HLA-D Region genomic polymorphism associated with Takayasu's arteritis. Angiology. 1990;41:421-6.

27. Nakao K, Ikeda M, Kimata S, Niitani H, Niyahara M. Takayasu's arteritis. Clinical report of eighty-four cases and immunological studies of seven cases. Circulation. 1967;35:1141-55.

28. Fraga A, Mintz G, Valle L, Flores-Izquierdo G. Takayasu's arteritis: frequency of systemic manifestations (study of 22 patients) and favorable response to maintenance steroid therapy with adrenocorticosteroids (12 patients). Arthritis Rheum. 1972;15:617-24.

29. Iga K, Gohma I, Hori K. Regression of the left main trunk lesion by steroid- administration in Takayasu aortitis. Chest. 1991;99: 508-10. 